ISSN electrónico: 2172-9077

DOI: http://dx.doi.org/10.14201/fjc201613187205

\title{
ASPECTOS ÉTICOS Y DEONTOLÓGICOS DE LA COBERTURA PE- RIODÍSTICA DE LAS CATÁSTROFES TECNOLÓGICAS: EL CASO DEL ACCIDENTE FERROVIARIO DE SANTIAGO DE COMPOSTELA (2013)
}

\section{Ethical and Deontological Aspects of Media Coverage in Technological Dis- asters: Case Study of the Santiago de Compostela Railway Accident (2013)}

\section{Lda. Alba ALMENARA}

Investigadora. Universidad de La Laguna, España

E-mail: carda-momos@hotmail.com

Fecha de recepción del artículo: 21/09/2016

Fecha de aceptación definitiva: 05/11/2016

\begin{abstract}
RESUMEN
Este estudio analiza los aspectos ético-deontológicos de la cobertura periodística de las catástrofes tecnológicas tomando como caso de estudio la catástrofe ferroviaria más grave de los últimos 40 años en España, acaecida el 24 de julio de 2013 en Santiago de Compostela. Se plantea, en primer lugar, una revisión sistemática de los documentos de autorregulación periodística españoles relacionados con la cobertura de accidentes, catástrofes, y particularmente catástrofes tecnológicas. En segundo lugar, se lleva a cabo un análisis del texto y de las fotografías tomando como muestra cuatro de los periódicos digitales de mayor influencia entre el público gallego y español. Los resultados permiten afirmar que las transgresiones deontológicas ocurren en mayor o menor medida en todos los medios digitales estudiados, tanto en fotografías como en texto. Finalmente se incluye una propuesta con recomendaciones para una mejor cobertura informativa en catástrofes tecnológicas, tomando como referencia los hallazgos obtenidos en los dos análisis previos.
\end{abstract}

Palabras clave: ética; deontología; medios de comunicación; catástrofes tecnológicas; Santiago de Compostela.

\begin{abstract}
This study examines the ethical-deontological aspects in media coverage of technological disasters, taking as case subject the most important railway accident in Spain of the last 40 years, which took place on the 24 of July 2013 in Santiago de Compostela. To do so, in first place, it presents a systematic review of Spanish self-regulation of journalistic documents related to the coverage of accidents, disasters, in particular technological disasters. Secondly, an analysis of text and photograph is carried out taking as examples four of the most influential online newspapers amongst the Spanish and Galician public media. The results allow us to confirm that deontological transgressions occurred to some extent in all the digital media studied, both in photographs and text. Lastly, a proposal is included with guidelines for a better coverage of technological disasters, using as a reference the findings of previous analysis.
\end{abstract}

Key words: ethics; deontology; media; technological disasters; Santiago de Compostela. 


\section{INTRODUCCIÓN}

La catástrofe ferroviaria más grave de los últimos 40 años en España tuvo lugar el 24 de julio de 2013 en Santiago de Compostela y causó la muerte a 79 personas. Realizar una cobertura informativa sobre catástrofes tecnológicas y trasladar a la ciudadanía los datos necesarios para que conozca los hechos puede resultar difícil, sobre todo porque el periodista ha de manejar información sensible y actuar en un escenario de estrés, urgencia y caos (Rodríguez y Odriozola, 2012). Así, los aspectos deontológicos resultan fundamentales en estos casos por el riesgo de colisión entre el derecho a la información de la ciudadanía y el derecho de los afectados a que se respete su intimidad y su imagen.

El interés por la investigación de este tema, y su enfoque deontológico, viene dado precisamente por la peculiar y delicada naturaleza de este tipo de coberturas. Si bien es cierto que una cobertura mediática debe ser rigurosa en cualquiera de sus formas, circunstancias y momentos, durante una catástrofe tecnológica - o cualquier tipo de catástrofe con víctimas humanas- se acrecienta, si cabe, la dificultad de tratar la información con sumo cuidado, diligencia y corrección. Informar sobre eventos de este tipo acarrea, en ocasiones, una gran complejidad para el profesional. Este debe trabajar con urgencia y actuar, al mismo tiempo, de manera respetuosa con las víctimas y sus allegados, intentando que el trauma que invade la escena no se convierta en un obstáculo. Al mismo tiempo se debe informar a la audiencia sin producir temor o provocar más dolor a los afectados, con el riesgo que corre el propio informador de verse afectado psicológicamente por los acontecimientos que cubre (Rodríguez y Odriozola, 2012). Estos eventos no solo se convierten en un reto profesional: el medio de comunicación también tiene que enfrentarse al desconcierto y a la ruptura imprevista del flujo informativo rutinario

Esta investigación pretende determinar cuál ha sido el comportamiento deontológico de la prensa digital española durante la cobertura de la catástrofe, si las quejas están justificadas y existieron vulneraciones éticas, tomado como muestra de análisis a los cuatro medios digitales más leídos en sus respectivos ámbitos de difusión - elmundo.es, elpais.com, lavozdegalicia.es, farodevigo.es-.

\section{LOS DESAFÍOS DEL PERIODISTA ANTE UNA CATÁSTROFE}

Una catástrofe resulta una ocasión de especial exigencia profesional para el periodista y el medio de comunicación. En estos casos se produce una ruptura del pulso informativo diario que obliga a atender una situación extrema, en muchos casos sin equipos de redacción reforzados para la ocasión. En el caso de los medios digitales, el evento dificulta el mantenimiento del rendimiento habitual de los servidores debido al súbito aumento de tráfico, y se produce una aceleración del suministro de noticias que impide la elaboración calmada de informaciones, con el consiguiente riesgo de error (Salaverría, 2006; Toledano y Ardèvol-Abreu, 2013).

Ejercer el periodismo en este tipo de situaciones extremas supone una responsabilidad compleja: los acontecimientos afectan y conmocionan a la sociedad a diferentes niveles hasta llegar a influir, en ocasiones, en el devenir de todo un país. Son hechos dramáticos, sensibles, que implican estados de shock además de circunstancias de urgencia, estrés y caos para todas las personas implicadas, incluido el periodista (Rodríguez y Odriozola, 2012). Además, este puede encontrar muchos obstáculos para desenvolverse por problemas en el transporte, la comunicación o por contratiempos de tipo logístico (Camps, 1999). El periodista se ve envuelto en un ambiente apresurado, maneja información a menudo muy sensible, tratando con personas en estado de shock y hallándose sobre un terreno en el que las condiciones de trabajo pueden no ser las mejores.

Aspirar a la máxima calidad informativa es siempre una exigencia, sin embargo, debido a los posibles inconvenientes que se acaban de reseñar, el riesgo de faltar a este estándar aumenta considerablemente. Asimismo, evitar la plasmar de manera morbosa los hechos dándoles al mismo tiempo el carácter humano que merecen resulta un gran ejercicio ético (Noguera, 2005). Siguiendo esta línea, Salaverría (2006) destaca que las catástrofes actúan como termómetros de la excelencia profesional periodística. Los medios de comunicación cumplen una función social muy importante en estas situaciones, pues pueden 
paliar el caos o impedir que continúe, tranquilizar y orientar a los afectados, prevenir a la población para que evite lugares o prácticas de riesgo, fomentar la solidaridad, promover la ayuda logística, etc. (Camps, 1999).

\section{EL ACCIDENTE FERROVIARIO Y LAS CRÍTICAS A SU COBERTURA}

Unos minutos antes de las nueve de la noche del 24 de julio de 2013, un tren Alvia procedente de Madrid descarrilaba en la pronunciada curva de A Grandeira, a apenas cuatro kilómetros de la estación de Santiago de Compostela. El convoy, de ocho vagones y operado por Renfe, transportaba un total de 238 personas. Muchos de los ocupantes fallecían en el acto o lo hacían conforme transcurren las horas debido a la gravedad de las heridas. Considerada como una de las catástrofes ferroviarias más graves de la historia de España y la peor de los últimos 40 años, costó la vida a un total de 79 personas y provocó varias decenas de heridos.

La cobertura informativa de esta catástrofe suscitó críticas, tanto de familiares como de periodistas, sobre todo por un exceso de «imágenes morbosas y virulentas» (Méndez, 2013), pero también por el tratamiento «no excesivamente digno» de las víctimas y el poco respeto al derecho a la intimidad de los afectados -varias personas reconocieron a sus familiares en las fotografías de los periódicos-. Además, tres meses después del descarrilamiento, la Asociación de la Prensa de Madrid (APM) pidió a la Comisión de Arbitraje, Quejas y Deontología de la Federación de Asociaciones de la Prensa de España (FAPE) la elaboración de unas pautas éticas para informar de este tipo de accidentes. Meses más tarde, fueron aprobadas las recomendaciones éticas o deontológicas de la FAPE para el tratamiento periodístico y mediático de las catástrofes (FAPE, 2014).

Cada catástrofe abre de nuevo la polémica sobre los límites entre el derecho a la intimidad de los protagonistas y la necesidad de información de la ciudadanía. Una de las fotografías difundidas durante la cobertura de la catástrofe de Santiago, en la que figuraba en primer plano una niña herida en brazos de un bombero, fue un ejemplo del debate que plantea la difusión o no de fotografías con contenidos cruentos en los medios. La Asociación de Periodistas de Santiago de Compostela (APSC) presentó una denuncia a la Comisión de Arbitraje, Quejas y Deontología de FAPE contra La Voz de Galicia por publicar dicha imagen ${ }^{1}$. Meses más tarde la comisión elaboró un dictamen en el que exponía lo siguiente:

Se ha estimado que este conjunto fotográfico no comporta lesión del principio de protección de la infancia; pues, si bien la niña que aparece en la fotografía es identificable, su imagen queda integrada en un protagonismo conjunto con el servidor público que la socorre, y con un mensaje de solidaridad ante la catástrofe que no implica especial sacrificio, demérito o conturbación de la intimidad ni de la dignidad de la niña, serena víctima de una situación trágica que aparece rescatada por quién [sic], también serenamente, cumple con su deber. La libre información debe prevalecer (FAPE, 2013, p. 1).

Según esta organización, la fotografía no infringiría el punto 4.d. de su código deontológico, que estipula que se ha de respetar el derecho a la intimidad de los menores (FAPE, 1993), como tampoco la pauta 4.6 que la misma federación redactó en sus recomendaciones para el tratamiento periodístico y mediático de las catástrofes y que expone que las imágenes de víctimas identificables podrían afectar gravemente a su intimidad (FAPE, 2014). Pese a haberse convertido en una fotografía polémica también fue una de las más famosas y difundidas en las portadas de las cabeceras extranjeras.

La queja de la APSC también denunciaba una fotografía publicada en la portada de la edición impresa de La Voz de Galicia pues, a su juicio, se atentaba contra la privacidad de las víctimas retratadas, ya que estas eran perfectamente identificables. Ante ello, la comisión de la FAPE vuelve a señalar que no

\footnotetext{
${ }^{1}$ Aunque más medios como El País también publicaron la fotografía, la denuncia se presentó formalmente contra el periódico local La Voz de Galicia porque la imagen fue tomada por Mónica Ferreiros, una de las fotógrafas del diario.
} 
existe intromisión en la intimidad de los protagonistas - pese a apuntar en una de sus recomendaciones para el tratamiento periodístico y mediático de las catástrofes que las imágenes de víctimas identificables podrían afectar gravemente a su intimidad-y que no se incumple ningún punto de su código deontológico.

En este caso la presencia de las víctimas en la imagen no ha sido utilizada ni con finalidad ni con resultado de descrédito, desprestigio o descalificación, ni es atentatoria a la dignidad de los afectados. Tampoco la imagen ahonda especialmente en el profundo dolor particular y general que causó el accidente noticiado (FAPE, 2014, p. 1).

\section{Documentos DE AUTORREgulación Y PAUTAS DEONTOLÓgicas SELECCIONADAS}

Para conocer la situación de los documentos de autorregulación españoles es pertinente detenerse en varios documentos nacionales dedicados específicamente a la cobertura de catástrofes, uno elaborado por el Consejo del Audiovisual de Cataluña (CAC) y dos por la FAPE, considerando que, hasta donde alcanzó esta investigación, estos son los únicos documentos de este tipo existentes en España. También resulta de obligatorio análisis el código deontológico de la Federación de Asociaciones de Periodistas de España (FAPE), ya que es el pionero de los códigos de autorregulación periodísticos a nivel estatal. Además, es conveniente analizar qué dictan los libros de estilo de cada medio estudiado, excepto el de Faro de Vigo debido a su inexistencia. Por último, se debe estudiar el libro de estilo de la Agencia Efe por su actualidad, vinculación con el periodismo para internet y por tratar el novedoso concepto de insinuación que se expone más adelante. En total, ocho documentos de autorregulación de características diferentes.

Puesto que los documentos de carácter más general se detienen en gran variedad de temas, situaciones y conflictos éticos, muchas veces no todas sus normas están relacionadas con las catástrofes, o dicho de otro modo, no todas ellas se pueden aplicar a una cobertura de catástrofes. Para llevar a cabo una sistematización que permita el análisis de las normas éticas más recogidas por todos los documentos, a continuación se exponen las pautas más recurrentes contempladas en ellos y que guardan relación con la naturaleza de la cobertura y la temática de las informaciones.

La primera de las pautas contempladas es la que habla de la intimidad y la propia imagen. El respeto de la intimidad de las víctimas y familiares durante la cobertura de una catástrofe tecnológica se convierte en un asunto que precisa la máxima diligencia profesional y es uno de los derechos más presentes en la mayoría de documentos estudiados. De manera general, la FAPE (1993) dicta en el artículo 4 de su código deontológico que

Sin perjuicio de proteger el derecho de los ciudadanos a estar informados, el periodista respetará el derecho de las personas a su propia intimidad e imagen, teniendo presente que solo la defensa del interés público justifica las intromisiones o indagaciones sobre la vida privada de una persona sin su previo consentimiento. Además en el tratamiento informativo de los asuntos en que medien elementos de dolor o aflicción en las personas afectadas, el periodista evitará la intromisión gratuita y las especulaciones innecesarias sobre sus sentimientos y circunstancias» FAPE, 1993.

En un documento elaborado posteriormente, la FAPE trata de desarrollar mejor el concepto de intromisión gratuita debido a su «indudable grado de ambigüedad» (FAPE, 2008, p. 5). Así señala que

En estas situaciones no queda otro remedio que remitirse al buen hacer profesional y la delicadeza espiritual del reportero [...]. En este buen hacer profesional intervienen, por lo menos, hasta tres distintos ingredien-

(C) Ediciones Universidad de Salamanca / CC BY - NC ND Fonseca, Journal of Communication, n. 13, 2016, pp. 187-205 
tes: sentido común, sensibilidad moral y capacidad para la compasión con la persona que sufre. Y estos ingredientes son más el resultado de la madurez humana personal del periodista que el efecto derivado de unas normas positivas de carácter deontológico (FAPE, 2008, p. 5).

Esta recomendación no redime al concepto 'intromisión gratuita' de la ambigüedad que la propia organización reconoció, puesto que no ofrece criterios prácticos sobre cómo actuar; en su lugar apela a la capacidad del periodista para orientarse en su labor. Por otro lado, el CAC (2001) señala que resulta imperativo respetar el derecho de las víctimas a la privacidad y que no es aceptable formular requerimientos a los afectados en circunstancias inadecuadas en las que medien dolor y sufrimiento, o cuando estos no dispongan de libertad efectiva de elección o decisión.

Otro documento de autorregulación que contempla la intromisión de la intimidad como una falta ética periodística es el libro de estilo de la Agencia Efe. Asegura que esta se produce cuando una información atenta contra la reputación, el buen nombre o la dignidad personal, o cuando una fotografía expone la vida íntima y/o privada de los retratados (2011). El libro de estilo de El Mundo también recoge la intromisión de la intimidad como falta ética, pero se limita a considerar únicamente la de los personajes públicos y famosos.

Finalmente, una de las recomendaciones de la FAPE para el tratamiento periodístico y mediático de las catástrofes expone que «las imágenes de víctimas identificables pueden afectar gravemente a su intimidad. Su utilización repetitiva ahonda gratuitamente (ya no es novedad) la afección de la intimidad» (FAPE, 2014, pp. 14-15). Además, precisa que especialmente los afectados por la tragedia, tanto víctimas como familiares, deben «ser respetados cuando la información tenga que referirse a ellos [porque se encuentran envueltos en circunstancias en las que] por sí mismos tienen pocos o nulos mecanismos de reparación» (FAPE, 2014, p. 12).

Otra pauta de interés es la que habla de la publicación del nombre, la situación personal, domicilio o población de procedencia de los involucrados en la tragedia. Puede englobarse dentro del derecho a la intimidad y se trata de una pauta que tan solo el CAC toma en cuenta. Para el consejo este tipo de datos no son adecuados pues «no siempre es relevante para la audiencia y, en ocasiones, puede incrementar el sufrimiento» (2001, p. 105). Dentro del amplio concepto de la intromisión de la intimidad, es pertinente tomar en consideración la pauta que regula la privacidad de las personas ingresadas en centros hospitalarios para una cobertura de catástrofes. Solo la FAPE (1993) se preocupa especialmente por la privacidad en esta situación y estipula que el periodista deberá evitar especialmente las intromisiones en la intimidad de personas ingresadas en centros hospitalarios o en instituciones similares ya que se encuentran en una situación de especial vulnerabilidad.

En lo que respecta a los menores de edad, según el CAC (2001), en general, y hasta donde sea posible, se debe evitar la participación de los menores de edad en este tipo de coberturas. Por su parte la FAPE (1993) dicta en su código deontológico que se ha de respetar el derecho a la intimidad de los menores. En las recomendaciones para el tratamiento periodístico y mediático de las catástrofes no hace nuevos incisos, declarando en el punto 6 que los 'principios comunes' ya estipulados en el código deontológico sobre la protección de la infancia son más que suficientes para aplicarse a situaciones especiales como el caso de una catástrofe (FAPE, 2014).

Aún más ambiguo, El Mundo (1996) señala que la protección de la intimidad en el caso de los menores admite 'menos excepciones'. Se entiende que el periodista ha de ser más riguroso con la intimidad de un menor de edad que con la de un adulto, pero no se especifica hasta qué punto ni se aportan concreciones. Por su parte, la Agencia Efe estipula que «donde las leyes lo condicionen, como el caso de España, debe evitarse por principio fotografiar a menores salvo autorización de los padres y en circunstancias en las que no suponga ningún prejuicio o menoscabo de sus derechos» (2011, p. 57).

Sobre el punto que habla de las fuentes y su atribución, el CAC estipula que es necesario proporcionar una cita clara y rigurosa de las fuentes utilizadas. Además, según el libro de estilo de La Voz de Galicia «en general, deben citarse las fuentes, pues ayudan al lector a valorar la fiabilidad de las infor- 
maciones y su posible orientación» (2002, p. 18). Sobre este aspecto, El País (2002) señala que ha de citarse obligatoriamente la fuente cuando el periodista no haya presenciado los hechos, es decir, cuando se trate de una narración de terceras personas.

Para la Agencia Efe (2011) todas las informaciones provienen de una fuente, y esta debe ser citada de la manera más precisa posible. Solo si el periodista presencia los hechos o se mencionan cuestiones de dominio público no es necesario especificar la fuente, como por ejemplo en una rueda de prensa o un espectáculo. Por último, El Mundo plasma en su libro de estilo que es preciso que el periodista se esfuerce por identificar la fuente para evitar al lector «esa desasosegante impresión de que el periodista se pasa de listo, se inventa lo que narra o es poseedor de la ciencia infusa» (1996, p. 100).

Siendo más que evidente que ofrecer rumores como hechos comprobados es una práctica poco ética, el periodista puede incurrir en otro tipo de error: publicar conjeturas y especulaciones. Referido a esto, el código deontológico de la FAPE señala que el periodista deberá diferenciar perfectamente las opiniones, interpretaciones y conjeturas de los hechos que cuenta, aunque no está obligado a ser neutral. Asimismo, el CAC (2001) también hace hincapié en evitar cualquier tipo de especulación que pueda producir temor o dudas a la audiencia. Por su parte, el libro de estilo de El País dicta que

El periodista transmite a los lectores noticias comprobadas, y se abstiene de incluir en ellas sus opiniones personales. Cuando un hecho no haya sido verificado suficientemente, el redactor evitará en las noticias expresiones como 'al parecer', 'podría', 'no se descarta' o similares. Estas fórmulas solo sirven para añadir hechos no contrastados o rumores. En ese caso deberá aportar los datos ciertos que le inducen a creer que algo 'podría' ocurrir o que ha sucedido 'al parecer' (2002, p. 21).

Como ya se mencionó, este es otro concepto analizado por las recomendaciones acerca del tratamiento informativo de las situaciones catastróficas de la FAPE. En lo referente a las 'especulaciones innecesarias', la organización concreta que deberían calificarse como tales las informaciones que supongan una amenaza contra «los valores de la democracia, el respeto a la dignidad humana o la propuesta de solución a los problemas mediante métodos violentos o intolerantes» (FAPE, 2008, p. 6).

Tras una catástrofe, es lógico que comience la búsqueda inmediata de su causante o culpable, por eso la regulación de la presunción de inocencia es otro punto a considerar. Según el CAC (2001) el periodista debe construir discursos y secuencias de causalidad con especial cautela, sin prejuzgar, atribuir culpabilidad o crear proyecciones de sospecha injustificadas. Esto resulta especialmente importante en la cobertura de accidentes y catástrofes tecnológicas, en las que con frecuencia se coloca en el punto de mira a conductores, maquinistas y pilotos. Siguiendo esta línea, el código deontológico de la FAPE (1993) recoge que el periodista debe trabajar con la premisa de que toda persona es inocente mientras no se demuestre lo contrario y, por si esto suscitaba dudas, la organización lo vuelve a recalcar en las recomendaciones para el tratamiento periodístico y mediático de las catástrofes, señalando que la presunción de inocencia también está vigente en las situaciones catastróficas (FAPE, 2014).

La Agencia Efe (2011) estipula que la presunción de inocencia obliga a los ciudadanos, incluidos los periodistas, a considerar a un encausado como inocente hasta que haya sido condenado. Asimismo, referido a este derecho incorpora el término insinuación, una de las «peores armas periodísticas para vulnerar la veracidad de las noticias [que] aunque no siempre resulta condenable en los tribunales [es] moral y profesionalmente reprobable» (2011, p. 280). La insinuación se vale de la yuxtaposición, a lo largo de la noticia, de elementos informativos dispares, y así se consigue sugerir o insinuar una relación de causalidad entre estos elementos, a menudo calumniosa, difamatoria y perjudicial (Agencia Efe, 2011). De esta manera ofrece el siguiente ejemplo: «Si se cuenta que la Policía informó del hallazgo de un cadáver y en otro párrafo que, según un vecino, la víctima había recibido amenazas de muerte de su pareja, se habrá sembrado una grave sospecha, sin prueba alguna, sobre la autoría de un crimen» (Agencia Efe, 2011, p. 280). Por todo ello es importante que el profesional de la información 
evite cualquier tipo de redacción que pueda proyectar insinuaciones de culpabilidad de los posibles responsables de la tragedia antes de una sentencia firme.

Referido a los contenidos cruentos y escabrosos en las fotografías el CAC (2001) es concreto en este sentido, pues señala que hay que evitar, como norma general, mostrar imágenes de víctimas mortales, personas heridas y féretros. Además, también estipula como reprobables los planos cortos de personas heridas, en shock o en situación de sufrimiento. Por otro lado, ni el código deontológico de la FAPE, ni sus recomendaciones para el tratamiento periodístico y mediático de las catástrofes, ni el libro de estilo de El Mundo (1996) precisa normas para este tipo de situaciones. Este último tan solo señala que no se debe traspasar la frontera de la crudeza y la truculencia, en especial en la información gráfica, y que se debe distinguir entre el interés público genuino y la curiosidad malsana.

Tampoco el libro de estilo de La Voz de Galicia (2002) hace una concreción demasiado exacta, pues se limita a exponer que no hay una norma universal: el periodista deberá sopesar en cada caso el valor informativo de la imagen. Por su parte el libro de estilo de El País (2002) estipula que las imágenes desagradables solo se publicarán cuando añadan información. Se entiende entonces que se divulgarán imágenes de ese tipo cuando resulten imprescindibles para que la información no quede incompleta o incomprensible. La Agencia Efe señala que en coberturas en las que puedan surgir imágenes desagradables, como los accidentes o catástrofes

Hay que evaluar su importancia periodística, el daño que se pueda ocasionar a la dignidad de la víctima y la aflicción de sus allegados. En cualquier caso, se recogerá en la toma solo lo que justifique el interés informativo, sin concesión a la morbosidad (2011, p. 58).

Tras esta revisión sistemática, se puede determinar que cada documento de autorregulación se preocupa de hacer hincapié en ciertos aspectos deontológicos frente a otros y que no existe un consenso claro. En la Tabla 1 se exponen los documentos estudiados y se señalan aquellas pautas que han sido tomadas en cuenta en sus páginas. Como ya se ha mencionado, cada uno hace una valoración distinta de una misma pauta: algunos se muestran más concretos y señalan específicamente qué consideran reprobable y otros en cambio muestran una gran carga de ambigüedad, obligando al periodista a aplicar su propio criterio. La intromisión en la intimidad, la atribución de fuentes y el descarte de contenidos cruentos en las fotografías son los temas más recurrentes en los documentos estudiados. La Tabla 1 indica las pautas que cada documento tomó en consideración y las que se decidieron obviar. 


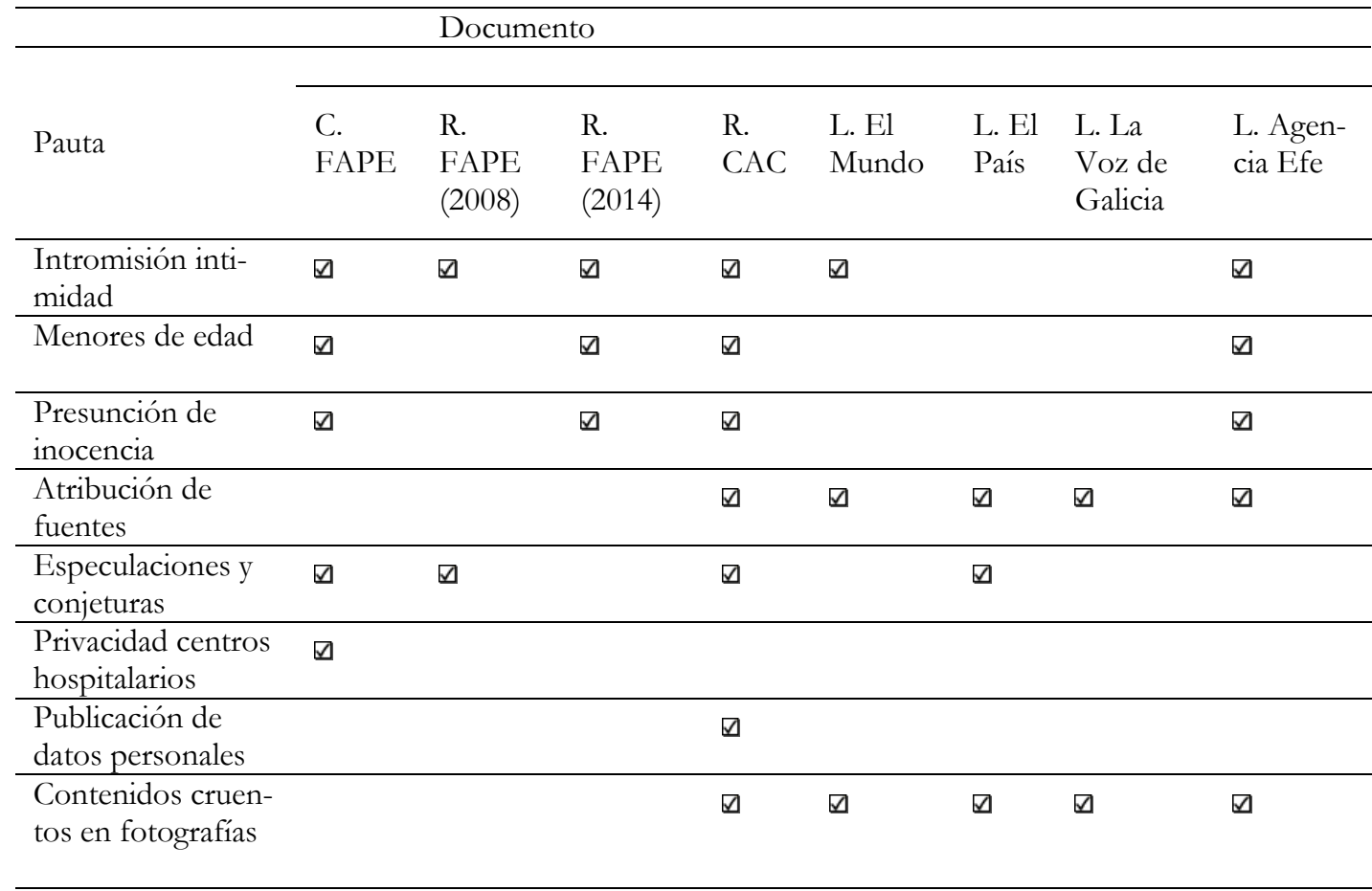

C.: Código; R.: Recomendaciones; L.: Libro de estilo

Elaboración propia.

Este trabajo pretende analizar hasta qué punto se justifican las llamadas de atención, previamente explicadas, por parte de varios sectores de la sociedad y determinar si efectivamente se produjeron vulneraciones deontológicas por parte de los medios estudiados. Con base en la revisión de la literatura mencionada, se plantea la primera pregunta de investigación:

PI1. ¿Cómo se comportaron los medios analizados desde el punto de vista deontológico? ¿Se transgredieron normas o recomendaciones?

En España, estudios como el de Ponts i Sorribes (2008) demuestran que las condiciones de emergencia y la situación de alteración emocional pueden conducir a los periodistas a vulnerar el derecho a la privacidad de las víctimas y a difundir un exceso de imágenes de dolor y sufrimiento. Puesto que la cobertura suscitó muchas críticas de familiares y periodistas -en especial por la publicación de imágenes que consideraban cruentas y el poco respeto a la intimidad de los protagonistas-, resulta de especial interés analizar cuál fue el tratamiento deontológico dado a las fotografías y si están justificadas esas críticas. Por ello se formula la siguiente hipótesis:

H1. Las imágenes de la catástrofe incluyeron contenidos cruentos y atentaron contra la intimidad de los protagonistas.

Puesto que el análisis se lleva a cabo en cuatro medios digitales diferentes, dos de ellos con lectores fundamentalmente españoles y otros dos con un predominio de usuarios gallegos, resulta pertinente plantear una segunda pregunta de investigación: 
PI2. ¿Se puede hablar de un comportamiento deontológico diferente de los medios 'nacionales' frente a los 'regionales'?2

\section{Metodología}

El universo de análisis del estudio comprendió los mensajes referidos al descarrilamiento de Santiago, pertenecientes al género informativo o interpretativo -como la noticia, la crónica, la entrevista y el reportaje- publicados en las ediciones digitales de la prensa de ámbito generalista, tanto 'nacional' como 'regional'. La muestra incluyó las informaciones aparecidas en los cuatro periódicos digitales 'nacionales' y 'regionales' con mayor número de usuarios: elmundo.es, elpais.com, lavozdegalicia.es y farodevigo.es. Se desecharon las piezas opinativas como el editorial, la columna y el artículo, y se tuvieron en cuenta las fotografías que acompañan a las piezas informativas y las galerías de fotos.

Se consideraron únicamente los mensajes que contaban con teaser en la página de inicio de la 'versión noche ${ }^{3}$ de cada medio. Así se aseguraba que la pieza poseyera un protagonismo importante en el medio que la difundiera, pues la página de inicio tiene una función análoga a las portadas del formato papel. Los teasers solo sirvieron como herramienta para determinar qué noticias han sido las más valoradas por los medios, pero no se llevó a cabo su análisis. Asimismo, se analizaron todas las galerías de fotos del periodo acotado, independientemente de si figuraban o no en la página de portada, por tratarse de un material que requiere especial cuidado ético. En total, la muestra incluyó 191 piezas informativas y 507 fotografías

El periodo de análisis comprendió ocho días: desde el miércoles 24 de julio de 2013, jornada en la que aconteció la catástrofe, hasta el miércoles 31 de julio de 2013, ambos inclusive. La decisión de seleccionar este período responde a la atención que los medios analizados dedicaron al tema -ya el 1 de agosto de 2013 la catástrofe aparece a la cola de las noticias de portada- y a que esta investigación se centra en analizar el escenario cuando aún está 'en caliente', en el clímax del flujo informativo, teniendo en cuenta que la construcción del relato de catástrofes sigue un patrón característico en el que las primeras etapas acogen los contenidos con mayor impacto emocional.

Se escogieron cuatro cabeceras digitales para el análisis: elmundo.es, elpais.com, lavozdegalicia.es y farodevigo.es. Las dos primeras cuentan con una audiencia predominantemente española y las dos últimas tienen especial calado sobre todo en la comunidad gallega. La razón para escoger medios digitales responde al hecho de que estos ofrecen una inmensa cantidad de imágenes, puesto que no hay límite de espacio, muy adecuada para el análisis visual, y además a que estos adquieren gran importancia ante un evento de emergencia o una calamidad. Siguiendo esta línea, García de Torres y Nicasio (2012) explican que en este tipo de coberturas los medios digitales adquieren gran relevancia por su capacidad para llegar rápida y efectivamente a gran número de usuarios. Por ello se puede suponer que fueron medios con una gran influencia, en especial los días siguientes al acontecimiento. Se consideraron los periódicos digitales con una mayor cantidad de usuarios únicos mensuales en fechas próximas al accidente, como indica la Tabla 2, puesto que este dato refleja la influencia social de cada medio.

\footnotetext{
${ }^{2}$ En rigor no puede hablarse de medios digitales 'regionales' o 'nacionales', puesto que todos son de alcance mundial. No obstante, los usuarios de lavozdegalicia.es y farodevigo.es son predominantemente gallegos.

${ }^{3}$ Se escogió esta versión porque era la única común a todos los medios. No resultó posible hacer un análisis de la versión 'mañana' o 'tarde' porque algunos medios la ofrecían y otros no.
} 
Tabla 2. Usuarios únicos en marzo de 2013 de los medios analizados.

\begin{tabular}{lc}
\hline \multicolumn{1}{c}{ Medio digital } & Usuarios únicos \\
\hline elmundo.es & 33.671 .537 \\
\hline elpais.com & 15.248 .000 \\
\hline lavozdegalicia.es & 4.562 .816 \\
\hline farodevigo.es & 1.331 .566
\end{tabular}

Fuente: ojdinteractiva.es y comScore.

\subsection{LIBROS DE CÓDIGOS}

Las preguntas de investigación y la hipótesis planteada requieren del estudio diferenciado del texto -titulares, subtítulos y cuerpo de texto- y de las fotografías - ubicadas tanto en los mensajes como en las galerías de fotos-. Puesto que se trata de dos materiales de naturaleza distinta es necesario llevar a cabo un análisis de contenido especial para cada uno de ellos; así este estudio cuenta con dos libros de códigos diferentes: uno para análisis de texto y otro para análisis de fotografías.

5.1.1. LIBRO DE CÓDIGOS PARA ANÁLISIS DE TEXTO. Se compone de dos apartados: datos básicos y escala deontológica.

5.1.1.1. DATOS BÁSICOS. A cada pieza informativa se le adjudicó un número correlativo para que pudiera ser localizada e identificada con mayor facilidad $(1,2,3 \ldots)$. A continuación, se señaló la cabecera a la que pertenecía la pieza informativa analizada (El País $=1$, El Mundo $=2$, La Voz de Galicia $=3$ y Faro de Vigo = 4). Después se indicó la fecha con el formato día/mes/año y la firma (periodista $=1$, redacción $=2$, agencia de noticias $=3$, y otros $=4$ ). Por último, se indicó la fuente principal (víctima $/$ familiar $/$ testigo $=1$, servicios de emergencia $=2$, institucional $=3$, gubernamental $=4$, fuente experta $=5$, judicial $/$ policial $=6$, no se especifica $/$ otros $=7$ ) y si la pieza venía o no acompañada de fotografía o galería de imágenes.

5.1.1.2. ESCALA DEONTOLÓGICA. Se compone de seis variables y se codificó con valor 0 cuando no se cumplía la premisa propuesta y con valor 1 cuando sí se cumplía: «Hay intromisión de la intimidad del/de los protagonista/s», «no se especifica la fuente», «hay especulaciones o conjeturas de los hechos, sus causas y sus consecuencias»; «no se respeta la presunción de inocencia», «figuran publicados el nombre, la situación personal, domicilio o población de procedencia de los involucrados en la tragedia» y por último «no se respeta la privacidad de las personas ingresadas en centros hospitalarios».

5.1.2. LibRO DE CÓDIGOS PARA ANÁLISIS DE FOTOGRAFÍAS. Como el anterior, este libro de códigos se compone de dos apartados: datos básicos y escala deontológica.

5.1.2.1. DATOS BÁSICOS. A cada fotografía publicada, independientemente de su ubicación en pieza informativa o galería de imágenes, se le adjudicó un número correlativo para que pudiera ser localizada e identificada con mayor facilidad. A continuación, se señaló su ubicación (en pieza informativa $=1 \mathrm{y}$ en galería de imágenes $=2)$. Después la cabecera a la que pertenecía $(E l$ País $=1, E l$ Mundo $=2$, La Voz de Galicia $=3$ y Faro de Vigo $=4$ ); la fecha de publicación codificada en el orden día $/$ mes $/$ año y la autoría (agencia de noticias $=1$, fotógrafo $=2$, redacción $=3$, no figura $=4$ y cedida =5). Por último se indicó el personaje principal que figura en ella (víctima/familiar $=1$, servicios de emergencia $=2$, institucional $=3$, gubernamental $=4$, fuente experta $=5$, judicial $/$ policial $=6$, no se distingue/otros $=7$ ). 
5.1.2.2. ESCALA DEONTOLÓGICA. Se compone de cinco variables y se codificó con valor 0 cuando no se cumplía la premisa propuesta y con valor 1 cuando sí se cumplía: «Figuran contenidos cruentos y escabrosos», «hay intromisión de la intimidad del/de los protagonista/s», «aparecen menores de edad en momentos de aflicción, dolor o desgracia evidente», «no se respeta la privacidad de las personas ingresadas en centros hospitalarios» y por último, «figuran publicados el nombre, la situación personal, domicilio o población de procedencia de los involucrados en la tragedia en la descripción o pie de la fotografía».

Para la elaboración de las escalas deontológicas se incluyó la compilación de las normas éticas consideradas más importantes -reseñadas y explicadas en la revisión bibliográfica-, pero sobre todo, de aquellas normas relacionadas con la cobertura de una catástrofe tecnológica (una aproximación similar puede observarse, por ejemplo, en Ardèvol-Abreu, 2009 o en Toledano y Ardèvol-Abreu, 2013). De esta manera, por ejemplo, sería absurdo plantear en el estudio una pauta que regulara la ética periodística en las informaciones relacionadas con las minorías étnicas, como recoge la Federación de Asociaciones de Periodistas de España (FAPE) en su código deontológico.

Ya con las normas seleccionadas, y analizadas en el marco teórico, se crearon dos escalas, que permitieran averiguar si se han cumplido, o por el contrario quebrantado, ciertas normas en cada formato, y responder a las preguntas de investigación y a la hipótesis. En una hoja de Microsoft Office Excel se introdujeron las variables reseñadas en el libro de códigos, y se llevó a cabo la codificación según las indicaciones explicadas en él. Posteriormente se exportaron los datos al programa IBM SPSS Statistics para Windows, versión 19, y se realizó el análisis estadístico. La Tabla 3 muestra los ítems empleados en la codificación.

Tabla 3. Escalas de vulneracioes deontológicas

Escala de vulneraciones deontológicas en textos

- Hay intromisión de la intimidad del/de los protagonista/s

- No se especifica la fuente

- Hay especulaciones o conjeturas de los hechos, sus causas y sus consecuencias

- No se respeta la presunción de inocencia

- Figuran publicados el nombre, la situación personal, domicilio o población de procedencia de los involucrados en la tragedia

- No se respeta la privacidad de las personas ingresadas en centros hospitalarios

Escala de vulneraciones deontológicas en fotografías

- Figuran contenidos cruentos y escabrosos

- Hay intromisión de la intimidad del/de los protagonista/s

- Aparecen menores de edad en momentos de aflicción, dolor o desgracia evidente

- No se respeta la privacidad de las personas ingresadas en centros hospitalarios

- Figuran publicados el nombre, la situación personal, domicilio o población de procedencia de los involucrados en la tragedia en la descripción o pie de la fotografía

\section{RESULTADOS}

Si se atiende a la cantidad de mensajes que difundieron los medios analizados durante el periodo acotado se puede determinar que los medios regionales dieron mayor cabida, y por tanto importancia, a la catástrofe de Santiago en su página de inicio con 78 noticias para lavozdegalicia.es y 45 para farodevigo.es. Por otro lado, fueron lavozdegalicia.es y elpais.com quienes publicaron mayor número de fotografías durante el periodo estudiado, con un total de 202 y 154 respectivamente. 


\subsection{Piezas informativas}

De todas las pautas deontológicas que se tuvieron en cuenta para el análisis de noticias, las más incumplidas fueron, por un lado, la que recomendaba no publicar datos personales de los protagonistas de la catástrofe -con 24 mensajes que sí lo hicieron- y, por otro, la que estipulaba que se debía citar la fuente de los datos que se aportaban en el mensaje - con 11 noticias que no citaron la fuente en alguno de sus datos-. En total, el 12,6\% de las noticias incluyó datos personales de los protagonistas sin que fueran ellos la fuente, y el 5,8 \% de los mensajes dejó sin citar algún dato presente en la pieza informativa. No solo se incumplieron estas pautas: como se detalla en la Tabla 4, todas las normas fueron vulneradas en mayor o menor medida, exceptuando la no intromisión en la privacidad de víctimas ingresadas en centros hospitalarios.

Tabla 4. Transgresiones deontológicas en texto, por norma vulnerada

\begin{tabular}{|c|c|c|}
\hline \multirow[t]{2}{*}{ Normas deontológicas } & \multicolumn{2}{|c|}{$\begin{array}{l}\text { Piezas informativas en las que se han detectado transgre- } \\
\text { siones }\end{array}$} \\
\hline & N. ${ }^{\circ}$ de noticias & Porcentaje sobre el total \\
\hline Intromisión intimidad & 6 & 3.1 \\
\hline $\begin{array}{l}\text { No se } \\
\text { especifica la fuente }\end{array}$ & 11 & 5.8 \\
\hline Especulaciones y conjeturas & 4 & 2.1 \\
\hline $\begin{array}{l}\text { No se respeta la } \\
\text { presunción de } \\
\text { inocencia }\end{array}$ & 5 & 2.6 \\
\hline Publicación de datos personales & 24 & 12.6 \\
\hline $\begin{array}{l}\text { No se respeta la privacidad en centros } \\
\text { hospitalarios }\end{array}$ & 0 & 0.0 \\
\hline
\end{tabular}

Nota: los porcentajes se han calculado en relación al número total de noticias de los cuatro perió$\operatorname{dicos}(\mathrm{n}=191)$.

Cada noticia vulneró un número determinado de pautas deontológicas: 158 noticias no vulneraron ninguna pauta, 21 noticias vulneraron solo una norma, ocho noticias vulneraron dos pautas, tres noticias vulneraron tres pautas y solo una de ellas vulneró cuatro de las seis pautas recogidas en la escala -el máximo registrado-. En total un 17,3\% de las noticias infringían al menos una de las normas deontológicas incluidas en la escala, es decir, 33 noticias de las 191 analizadas, como se muestra en la Tabla 5.

Tabla 5. Número total de vulneraciones deontológicas en texto

\begin{tabular}{lcc}
\hline Número de vulneraciones & N. $^{\circ}$ de noticias & $\begin{array}{c}\text { Porcentaje sobre } \\
\text { el total }\end{array}$ \\
\hline Ninguna & 158 & 82.7 \\
\hline Una & 21 & 11.0 \\
\hline Dos & 8 & 4.2 \\
\hline Tres & 3 & 1.6 \\
\hline Cuatro & 1 & 0.5 \\
\hline Más de cuatro & 0 & 0.0 \\
\hline Nota: las frecuencias y los porcentajes se han calculado en relación al número \\
total de noticias de los cuatro periódicos $(\mathrm{n}=191)$.
\end{tabular}

La noticia que más pautas infringió, y en este caso la más reprobable deontológicamente, se publicó en El País el 26 de julio de 2013 (Tejedor, E y Duva, J.). Incumple cuatro de las seis pautas deon- 
tológicas seleccionadas para análisis de texto. Se detectó una intromisión en la privacidad del protagonista -en este caso el maquinista-, pues se aportaban datos de su vida íntima tales como los motivos personales que le llevaron a pedir su traslado a Galicia. Asimismo, no se respetó su presunción de inocencia, ya que la construcción del texto sugiere que el maquinista solía manejar a velocidades 'inadecuadas'. Tampoco se especifica la fuente de algunos datos aportados y figuran datos personales del protagonista.

Para responder a la hipótesis y las preguntas de investigación en lo relativo a los textos, se creó una nueva variable mediante la suma simple de los ítems que componían la escala de vulneraciones deontológicas en texto. Tras crear esta variable se decidió eliminar el último ítem de la escala de textos, 'no se respeta la privacidad de las personas ingresadas en centros hospitalarios', pues en realidad, como muestra la Tabla 4, se comportaba como una constante (ninguna pieza vulneró esta norma). La Tabla 6 muestra la escala finalmente utilizada.

Tabla 6. Escala depurada de vulneraciones deontológicas en textos

- Hay intromisión de la intimidad del/de los protagonista/s

- No se especifica la fuente

- Hay especulaciones o conjeturas de los hechos, sus causas y sus consecuencias

- No se respeta la presunción de inocencia

- Figuran publicados el nombre, la situación personal, domicilio o población de procedencia de los involucrados en la tragedia

Así, se pudo valorar, en cada pieza informativa, su comportamiento deontológico global en lo relativo a la información textual. A mayor puntuación obtenida en esta nueva variable, mayor número de vulneraciones deontológicas en texto. Así, una información en la que se hubieran transgredido todos los ítems de la escala obtendría una puntuación de 5 (pues la escala consta de cinco elementos). La Tabla 7 muestra los resultados obtenidos por cibermedio.

Tabla 7. Transgresiones deontológicas en texto, por medio digital

\begin{tabular}{lccc}
\hline Medio & N. ${ }^{\circ}$ de noticias & $\begin{array}{c}\text { Media } \\
\text { vulneraciones }\end{array}$ & Desviación típica \\
\hline elpais.com & 33 & 0.67 & 1.051 \\
\hline elmundo.es & 35 & 0.26 & 0.701 \\
\hline lavozdegalicia.es & 78 & 0.19 & 0.485 \\
\hline farodevigo.es & 45 & 0.09 & 0.358 \\
\hline Total & 191 & 0.26 & 0.661 \\
\hline
\end{tabular}

Nota: La media de vulneraciones podía alcanzar valores teóricos comprendidos entre 0 (ninguna vulneración) o 5 (vulneración de los 5 ítems).

El medio digital que más vulneraciones cometió en el conjunto de sus textos fue la versión digital de El País, con un 0,67 de media, frente a la versión digital de Faro de Vigo con un 0,09. Para valorar la significación estadística de estas diferencias se llevó a cabo una prueba ANOVA. En este caso, el resultado obtenido determinó que existen diferencias importantes entre medios digitales $[F(3,187)=$ $5.87, p<.001)]$. A continuación, se procedió a analizar entre qué medios se dan esas diferencias significativas, para lo que se llevaron a cabo las pruebas post hoc de Bonferroni y estas indicaron que la media de vulneraciones de elpais.com $(M=0.67, D T=1.05)$ es significativamente más alta que las de ambos medios regionales -lavozdegalicia.es $(M=0.19, D T=0.49)(p<.01)$ y farodevigo.es $(M=0.09, D T=0.36)$ $(p<.01)-$. Se puede afirmar que este medio vulneró en más ocasiones que las cabeceras regionales las normas deontológicas para textos. En cuanto al resto de diferencias, ninguna resulta significativa: pese 
a que la diferencia entre la versión digital de El País y El Mundo es aparentemente alta $-0,67$ frente a 0,26 , respectivamente- la prueba post hoc de Bonferroni es solo marginalmente significativa $(p=.053)$.

\subsection{FOTOGRAFÍAS}

Las pautas que más se incumplieron en las fotografías fueron las relativas al respeto a la intimidad -con 109 casos-, y a los contenidos cruentos, -con 75-. En total, un 21,5\% de las fotografías vulneraron de alguna manera la intimidad de los protagonistas, ya fuera por la publicación de imágenes de víctimas identificables o familiares en estado de sufrimiento. Además, en un 14,8\% de las imágenes figuraban contenidos cruentos, como heridos o víctimas mortales reconocibles. No solo se incumplieron estas pautas: todas las normas fueron quebrantadas en mayor o menor medida, exceptuando, de nuevo, la no intromisión en la privacidad de víctimas ingresadas en centros hospitalarios, como se señala en la tabla 8.

Tabla 8. Transgresiones deontológicas en fotografías, por norma vulnerada

\begin{tabular}{lcc}
\hline \multirow{2}{*}{ Normas deontológicas } & \multicolumn{2}{c}{ Fotografías en las que se han detectado transgresiones } \\
\cline { 2 - 3 } & N. $^{\text {o de fotografías }}$ & Porcentaje sobre el total \\
\hline Contenidos cruentos & 75 & 14.8 \\
\hline Intromisión intimidad & 109 & 21.5 \\
\hline Menores de edad & 11 & 2.2 \\
\hline $\begin{array}{l}\text { No se respeta la privacidad en centros } \\
\text { hospitalarios }\end{array}$ & 0 & 0.0 \\
\hline $\begin{array}{l}\text { Publicación de datos personales en pie } \\
\text { de foto }\end{array}$ & 35 & 6.9 \\
\hline
\end{tabular}

Nota: los porcentajes se han calculado en relación al número total de fotografías de los cuatro periódicos $(\mathrm{n}=507)$.

Cada fotografía vulneró un número determinado de pautas deontológicas: 362 fotografías no vulneraron ninguna, 70 imágenes vulneraron solo una, 65 fotografías vulneraron dos, y 10 fotografías vulneraron tres. En total un $28,6 \%$ de las fotografías incumplió al menos una pauta deontológica, en decir, 145 de las 507 analizadas.

Tabla 9. Número total de vulneraciones deontológicas en fotografías

\begin{tabular}{lcc}
\hline Número de vulneraciones & N. ${ }^{\circ}$ de fotografías & $\begin{array}{c}\text { Porcentaje } \\
\text { sobre el total }\end{array}$ \\
\hline Ninguna & 362 & 71.4 \\
\hline Una & 70 & 13.8 \\
\hline Dos & 65 & 12.8 \\
\hline Tres & 10 & 2.0 \\
\hline Más de tres & 0 & 0 \\
\hline
\end{tabular}

Nota: las frecuencias y los porcentajes se han calculado en relación al número total de noticias de los cuatro periódicos $(\mathrm{n}=507)$.

A continuación, se muestra una de las 10 imágenes que más pautas infringió y, por tanto, una de las más reprobables de la muestra. La fotografía muestra contenidos cruentos, en este caso una herida, y por tanto también se vulnera su derecho a la intimidad. Pero es que, además, se trata de una menor de edad «en estado de aflicción o desgracia evidente». 


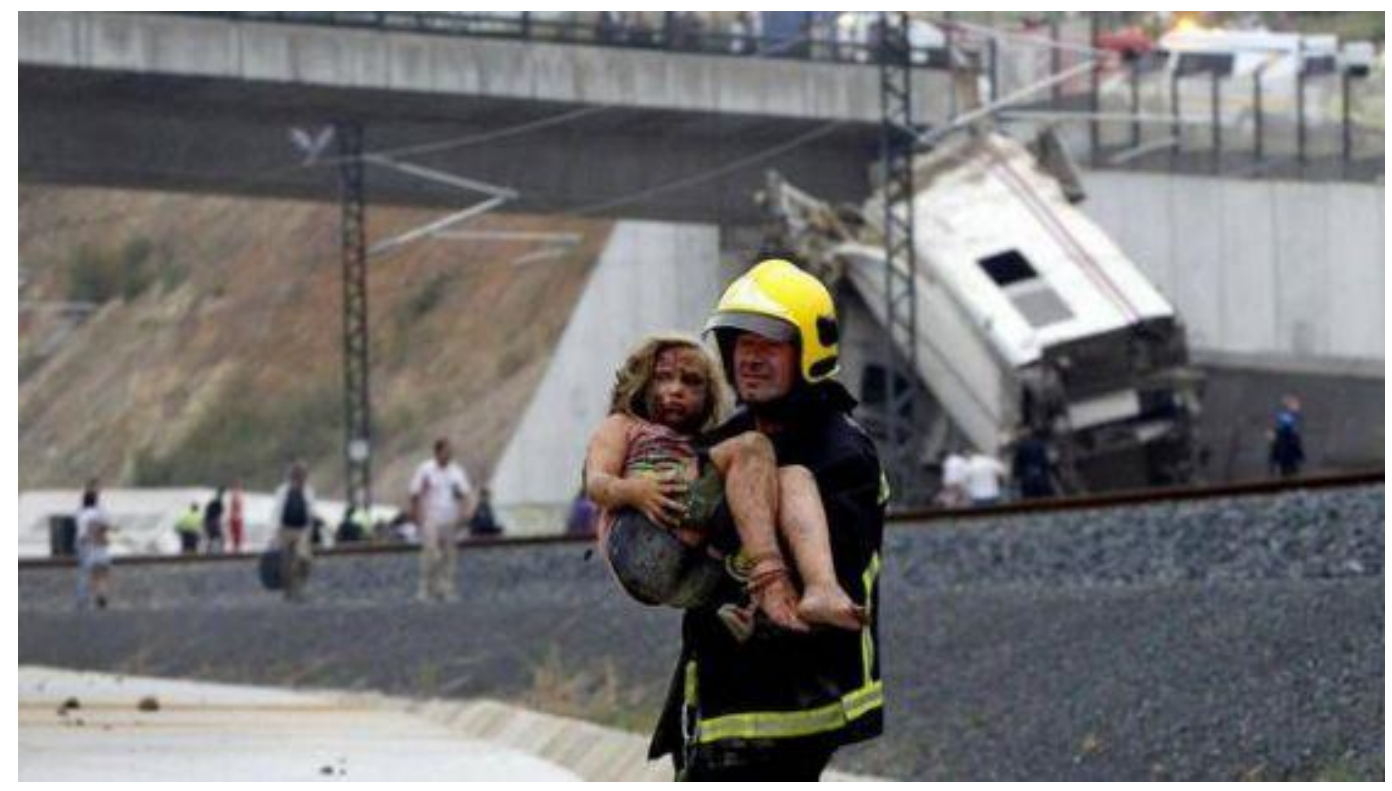

De manera análoga a lo que se hizo para el análisis de textos, se creó una nueva variable mediante la suma simple de los ítems que componían la escala de las vulneraciones deontológicas en fotografías. Como ocurrió con la escala de texto, después de crear esta variable se decidió eliminar el ítem 'no se respeta la privacidad de las personas ingresadas en centros hospitalarios', ya que no existía ninguna imagen que vulnerara esa norma, como muestra la Tabla 8. En la Tabla 10 aparece la escala una vez depurada.

Tabla 10. Escala depurada de vulneraciones deontológicas en fotografías

\begin{tabular}{l}
\hline - Figuran contenidos cruentos y escabrosos \\
- Hay intromisión de la intimidad del/de los protagonista/s \\
- Aparecen menores de edad en momentos de aflicción, dolor o desgracia evidente \\
- Figuran publicados el nombre, la situación personal, domicilio o población de procedencia de los \\
involucrados en la tragedia en la descripción o pie de la fotografía
\end{tabular}

De esta forma se pudo valorar, en cada fotografía, su comportamiento deontológico en función de los ítems de la escala. A mayor puntuación obtenida en cada una de esta nueva variable, mayor número de vulneraciones deontológicas. Así, una imagen que vulnerase los cuatro ítems de su escala obtendría una puntuación de 4 (pues la escala está compuesta de cuatro elementos). En cambio, una imagen que obtuviese una puntuación de 0 no habría vulnerado ningún ítem. A continuación, para determinar el mejor o peor comportamiento deontológico de cada medio se calculó la media de vulneraciones por cada periódico digital, reflejada en la Tabla 11. 
Tabla 11. Transgresiones deontológicas en fotografías, por medio digital

\begin{tabular}{lccc}
\multicolumn{5}{c}{ Tabla 11. Transgresiones deontológicas en fotografías, por medio digital } \\
\hline Medio & N. ${ }^{\circ}$ de fotografías & $\begin{array}{c}\text { Media } \\
\text { vulneraciones }\end{array}$ & Desviación típica \\
\hline Elpais.com & 154 & 0.41 & 0.682 \\
\hline Elmundo.es & 115 & 0.40 & 0.686 \\
\hline Lavozdegalicia.es & 202 & 0.49 & 0.877 \\
\hline Farodevigo.es & 36 & 0.64 & 0.990 \\
\hline Total & 507 & 0.45 & 0.790
\end{tabular}

En la Tabla 11 se observa que el medio digital que más quebrantó los documentos de autorregulación con sus fotografías fue farodevigo.es, con un 0,64 de media, mientras que la media más baja correspondió a elmundo.es con 0,40 . Tras hacer la prueba ANOVA con las medias recogidas en la tabla 13 , se determina que las diferencias entre medios no son significativas $[F(3,503)=1.108, p=.345)]$.

La primera pregunta de investigación se refería al comportamiento deontológico de los medios en la cobertura de la catástrofe. El análisis llevado a cabo demuestra que los medios incumplieron normas deontológicas en mayor o menor medida, tanto en las fotografías como en el texto de los mensajes. Los resultados demuestran que las pautas más incumplidas en las fotografías fueron las relacionadas con el respeto a la intimidad de los protagonistas - con un $21,5 \%$ de imágenes que no la respetaron- y con los contenidos cruentos de las imágenes - con un 14,8\% de las fotografías que la incumplieron-. Por su parte, las pautas más quebrantadas en el texto fueron las relativas a la citación de fuentes -con un $5,8 \%$ de textos que la incumplieron- y la que recomendaba no publicar datos personales de las víctimas aun con el consentimiento previo a los familiares - con un $12,6 \%$ de textos que publicaron estos datos-. El medio que más transgresiones cometió en sus fotografías fue la versión digital de Faro de Vigo y el que menos elmundo.es. El medio que más vulneraciones cometió en sus textos fue elpais.com y el que menos farodevigo.es. En lo relativo a los textos, los resultados constatan un mejor comportamiento deontológico de los medios regionales (Faro de Vigo y La Voz de Galicia). Elpais.com y elmundo.es mostraron medias más altas en la escala de transgresiones, aunque las diferencias resultaron estadísticamente significativas solo para El País frente a Faro de Vigo y La Voz de Galicia.

Los análisis referidos a las fotografías muestran un comportamiento deontológico similar entre los cuatro medios, que no ofrecen diferencias estadísticamente significativas. Un 17,3\% de noticias infringieron al menos una de las normas éticas de las consideradas en la investigación, mientras que este porcentaje fue del 28,6 para las imágenes. Estos datos demuestran que el formato que en el que se produjeron más transgresiones fue el visual.

La hipótesis de la investigación planteaba que las imágenes de la catástrofe incluían contenidos cruentos y atentaban contra la intimidad de los protagonistas, teniendo en cuenta las críticas tan específicas que se hicieron de las fotografías de la cobertura. La hipótesis se verifica, pues un 14,8\% de las imágenes contenía planos de heridos y víctimas mortales identificables y un $21,5 \%$ no respetaba la privacidad de los protagonistas.

La segunda pregunta de investigación planteaba si se podía hablar de un comportamiento deontológico diferente de los medios 'nacionales' frente a los 'regionales'. Los análisis estadísticos no permiten concluir que exista un comportamiento diferenciado entre ediciones regionales y nacionales en las fotografías. En cambio, sí se puede apuntar una tendencia en lo relativo a los textos, ya que los medios regionales mostraron un mejor comportamiento deontológico. La versión digital de El País muestra medias significativamente más altas que los dos medios gallegos. Las medias de elmundo.es también son más altas que las de los dos periódicos 'regionales', aunque las diferencias no llegan a ser significativas con los estadísticos utilizados. 


\section{DISCUSIÓN Y CONCLUSIONES}

Esta investigación demuestra que las transgresiones deontológicas ocurren en mayor o menor medida en todos los medios digitales estudiados, tanto en los textos como en las fotografías. Pese a todo, el mayor porcentaje de transgresiones se produjo en el formato visual: la protección de la privacidad de los protagonistas y la no inclusión de contenidos cruentos fueron los aspectos éticos más vulnerados. En los textos, se descuidó especialmente la citación de fuentes y se difundieron con frecuencia datos personales como el domicilio de los protagonistas y detalles de su vida privada. Esto demuestra que, o bien se vigila con mayor celo la ética en los textos que en las fotografías, o bien resulta más complejo comportarse de manera deontológicamente correcta con las imágenes.

$\mathrm{Al}$ igual que sucedió con el tratamiento informativo del derrumbe de un túnel en el barrio de El Carmel en Barcelona (Pont i Sorribes, 2008), en la cobertura de la catástrofe de Santiago se vulneró la privacidad de las víctimas y reiteración de escenas de dolor y sufrimiento. Lo deseable sería que no se repitieran estas transgresiones si se quiere cumplir una función social de manera adecuada. Al ser las pautas deontológicas más transgredidas las que recomiendan no incluir contenidos cruentos y las que aconsejan respetar la privacidad de los protagonistas, se demuestra que las quejas de familiares y periodistas estaban justificadas.

Se ha demostrado que la edición digital de Faro de Vigo fue la que menos transgresiones cometió en sus textos. Aunque no se ha estudiado la procedencia de las noticias, el resultado podría deberse a que este medio incluyese con mayor frecuencia informaciones procedentes de agencia, que, en general, presentan un tono más aséptico y menos valorativo. Sería deseable para próximos estudios valorar la posible relación entre el número de noticias de agencia y el comportamiento deontológico.

En el apartado visual, una de las la fotografías que vulneraron mayor número de ítems de la escala -protagonizada por una niña y un bombero- produjo gran polémica social, lo que de algún modo indica que la escala propuesta en este estudio es válida. La resolución de la FAPE sobre esta fotografía aseguró que la imagen no incumplía ninguno de los preceptos creados por la Federación, ni los pertenecientes a su código deontológico ni los recogidos en sus recomendaciones. Este ejemplo es una muestra del profundo grado de ambigüedad que arrastran la mayoría de preceptos de los documentos de autorregulación y la disparidad de opiniones y criterios e incongruencias dentro de las propias organizaciones. Pese a todo, según el criterio seguido en la codificación de esta investigación, la fotografía de la menor de edad y el bombero incumplirían tres puntos de las recomendaciones del CAC, un punto de las recomendaciones FAPE y un punto del libro de estilo de la Agencia Efe.

La ilustración de momentos dolorosos y trágicos y la publicación de imágenes de heridos y víctimas mortales continúan creando debate y profunda polémica, pues a menudo se produce una colisión entre el derecho de los ciudadanos a la información y el derecho a la intimidad de las personas que aparecen. No es sencillo establecer una delimitación clara que funcione a gusto de todos y bajo todas las circunstancias, y quizás de ahí surja el alto grado de imprecisión en la mayoría de documentos analizados.

Puede que no sea realista plantear una norma universal, pero sí un límite de actuación ${ }^{4}$. Las catástrofes tecnológicas son un hecho más y como tal deben ser contadas a la ciudadanía. No hay que pretender silenciar la muerte y transformarla en un tabú en los medios, pero sí tratar de satisfacer la demanda de información de la ciudadanía sin causar prejuicio a otros. Este sería el equilibrio perfecto.

La autorregulación periodística debe ayudar a afrontar los eventos catastróficos con mayor diligencia profesional. Esta nace fruto del consenso voluntario de todos los actores que participan en el proceso de comunicación. No se trata de censura: atiende a un ejercicio de responsabilidad y compromiso con los fines y valores del periodismo. Precisamente porque surge fruto de un acuerdo con-

\footnotetext{
${ }^{4}$ Con 'límite de actuación' se hace referencia al establecimiento de un 'minimum invulnerable', como el respeto a la dignidad de los protagonistas. En el decálogo propuesto más adelante se tratan de establecer mecanismos que favorezcan ese respeto como, por ejemplo, el pixelado del rostro de los protagonistas, en el caso de que sea necesario difundir una fotografía en la que figuren en un estado de vulnerabilidad evidente.
}

(C) Ediciones Universidad de Salamanca / CC BY - NC ND Fonseca, Journal of Communication, n. 13, 2016, pp. 187-205 
junto, sus pautas, recomendaciones y normas no son coactivas como las del derecho, y pueden no ser aplicadas en determinadas circunstancias (Aznar, 2005). La deontología y la autorregulación mantienen una estrecha relación, pues si bien la primera se encarga de reflexionar y precisar pautas éticas, la segunda es la encargada de dar efectividad a estas reflexiones (Aznar, 1999) a través de multitud de mecanismos: los códigos deontológicos, las recomendaciones, el defensor del lector, los estatutos de redacción y los libros de estilo son solo algunos de ellos. Durante la cobertura de una catástrofe los periodistas deben emplearse a fondo, hacer un esfuerzo superlativo y contar los hechos con el máximo de respeto. No se trata de una simple rueda de prensa, sino de un acontecimiento que conmociona a toda una comunidad y como tal no debe ser tomado a la ligera. El periodista debe asumir que se le encomienda una tarea especialmente pesada, compleja y de gran responsabilidad y que se encuentra ante una experiencia que pondrá a prueba su capacidad no solo como profesional sino también como ser humano. Si no está dispuesto a asumir tales condiciones que desestime informar sobre estos eventos.

\section{REFERENCIAS}

Agencia Efe (2011). Libro del estilo urgente. Barcelona: Galaxia Gutenberg.

Ardèvol-Abreu, A. (2009). Información sobre inmigración en la prensa de Tenerife. Las manifestaciones de vecinos contra un centro de menores inmigrantes en 2006. RUTA - Revista Universitària de Treballs Acadèmics, 2, 1-24. Recuperado de: http://www.raco.cat/index.php/ Ruta/article/view/140228/191414

Aznar, H. (1999). Comunicación responsable. Deontología y autorregulación de los medios. Barcelona: Ariel.

Aznar, H. (1999). Ética y periodismo. Códigos, estatutos y otros documentos de autorregulación. Barcelona: Paidós.

Aznar, H. (2005). Ética de la comunicación y nuevos retos sociales. Códigos y recomendaciones para los medios. Barcelona: Paidós.

Camps, S. (1999). Periodismo sobre catástrofes. Cómo cubrir catástrofes, emergencias y accidentes en medios de transporte. Buenos Aires: Paulinas.

Consejo del Audiovisual de Cataluña (2001). Recomendaciones sobre el tratamiento informativo de las tragedias personales. En H. Aznar (2005), Ética de la comunicación y nuevos retos sociales. Códigos y recomendaciones para los medios (pp. 97-105). Barcelona: Paidós.

El Mundo (1996). Libro de estilo. Madrid: Temas de Hoy.

El País (2002). Libro de estilo. Madrid: Santillana.

Federación de Asociaciones de Periodistas de España (1993). Código deontológico. Recuperado de: http:// fape.es/home/codigo-deontologico

Federación de Asociaciones de Periodistas de España (2008). Informe/ resolución 2008/24 de la Federación de Asociaciones de Periodistas de España. Recomendaciones acerca del tratamiento informativo de las situaciones catastróficas. Recuperado de: http://www.comisiondequejas.com/wpcontent/uploads/24.pdf

Federación de Asociaciones de Periodistas de España (2013). Resolución 2013/75. Denuncia de la Asociación de la Prensa de Santiago de Compostela contra "La Voz de Galicia" en relación con un reportaje fotográfico sobre la catástrofe ferroviaria de Santiago de Compostela. Recuperado de: http://www.comisiondequejas.com/Resoluciones/Relacion/75.pdf

Federación de Asociaciones de Periodistas de España (2014). Informe / resolución 2014/85. Recomendaciones éticas o deontológicas para el tratamiento periodístico y mediático de las catástrofes. Recuperado de: http://www.comisiondequejas.com/wp-content/uploads/2015/09/85.pdf

García de Torres, E. y Nicasio, B. (2012). La vigencia de los patrones clásicos de cobertura de las catástrofes naturales en la era de Internet. Correspondencias \& Análisis, 2, 59-79. Recuperado de: http://www.correspondenciasyanalisis.com/es/pdf/cnt/3 vigencia patrones.pdf 
La Voz de Galicia (2002). Libro de estilo. Recuperado de: http://www.prensaescuela.es/web/archivos/lestivoz.pdf

Méndez, X. (29 de julio de 2013). 'En la cobertura del descarrilamiento a veces se ha traspasado la línea de la ética'. El Mundo. Recuperado de: http://www.elmundo.es/elmundo/ 2013/07/29/comunicacion/1375109983.html

Noguera, J. (2005). Informar emociones. El lenguaje periodístico en la cobertura de catástrofes. Colección comunicación, LibrosEnRed. Recuperado de: http://www.librosenred.com/libros/ informaremocionesellenguajeperiodisticoenlacoberturadecatastrofes.html

Pont i Sorribes, C. (2008). Análisis de las fuentes informativas y del respeto deontológico en situaciones de crisis: el tratamiento mediático del 'caso Carmel' de Barcelona. Quaderns del CAC, 31-32, pp. 141-147. Recuperado de: http://www.cac.cat/pfw files/cma/recerca/quaderns cac/ Q31-32 Pont ES.pdf

Rodríguez, P. y Odriozola, B. (2012). Catástrofes y periodismo: el relato, los escenarios, las interacciones y las necesidades prácticas y psicológicas de todos los implicados. Estudios sobre el Mensaje Periodístico, 18(2), 577-594. Recuperado de: http://revistas.ucm.es/index.php/ESMP/article/viewFile/41033/39280

Salaverría, R. (2006). Los cibermedios ante las catástrofes: del 11S al 11M. En A. Vara, J. R. Virgili, E. Giménez y M. Díaz (2006), Cobertura informativa del 11-M (pp. 29-45). Pamplona: EUNSA.

Tejedor, E. y Duva, J. (26 de julio de 2013). El piloto que descarriló su suerte. El País. Recuperado de: http://ccaa.elpais.com/ccaa/2013/07/25/galicia/1374755988_825305.html

Toledano, S. y Ardèvol-Abreu (2013). Los medios ante las cata $\square$ strofes y crisis humanitarias: propuestas para una funcio $\square \mathrm{n}$ social del periodismo. Communication \& Society, 26(3), 190-213. Recuperado de: http://dadun.unav.edu/bitstream/10171/35516/1/20130627142821.pdf 